\title{
3-Methyladenine and dexmedetomidine reverse lipopolysaccharide-induced acute lung injury through the inhibition of inflammation and autophagy
}

\author{
DENGFENG DING ${ }^{1,2}$, SHIYUAN XU ${ }^{1}$, HONGFEI ZHANG $^{1}$, WEI ZHAO ${ }^{1}$, XUEPING ZHANG $^{2}$, \\ YUANXU JIANG $^{2}$, PING WANG ${ }^{2}$, ZHONGLIANG DAI $^{2}$ and JUNZHI ZHANG ${ }^{2}$
}

${ }^{1}$ Department of Anesthesiology, Zhujiang Hospital, Southern Medical University, Guangzhou, Guangdong 510282;
${ }^{2}$ Department of Anesthesiology, Shenzhen People's Hospital, Jinan University, Shenzhen, Guangdong 518020, P.R. China

Received July 19, 2016; Accepted March 31, 2017

DOI: $10.3892 / \mathrm{etm} .2018 .5832$

\begin{abstract}
The aim of the present study was to investigate the effects of 3-methyladenine (3-MA) and dexmedetomidine (DEX) pretreatment on lipopolysaccharide (LPS)-induced acute lung injury (ALI) and the potential mechanism underlying the effects. LPS was instilled into the trachea of BALB/c mice to induce the ALI model. Solutions of 3-MA or DEX were intravenously injected into the mice $1 \mathrm{~h}$ later to establish the 3-MA and DEX groups. On days 1, 3 and 5 after the injections, arterial blood gas analysis was conducted, and the lung wet-dry weight ratio (W/D) was determined. In addition, albumin, cytokine and myeloperoxidase (MPO) contents were evaluated using ELISAs, and hematoxylin and eosin (H\&E) staining was conducted. Furthermore, western blot analysis was used to evaluate the protein expression levels of microtubule-associated protein 1A/1B-light chain 3 (LC3)-I, LC3-II, autophagy protein 5 (ATG5), Rab7 and lysosome-associated membrane protein 1 (LAMP1), and reverse transcription quantitative polymerase chain reaction (RT-qPCR) was used to detect the mRNA expression levels of nuclear factor $-\mathrm{kB}$ $(\mathrm{NF}-\kappa \mathrm{B})$ and Toll-like receptor 4 (TLR4). Treatment with 3-MA or DEX increased the blood partial pressure of oxygen level compared with that in the model group, and restored the W/D and blood partial pressure of carbon dioxide to normal levels. The content of tumor necrosis factor- $\alpha$, interleukin- 6
\end{abstract}

Correspondence to: Professor Shiyuan Xu, Department of Anesthesiology, Zhujiang Hospital, Southern Medical University, 253 Middle Gongye Street, Guangzhou, Guangdong 510282, P.R. China

E-mail: xsy998@smu.edu.cn

Abbreviations: 3-MA, 3-methyladenine; DEX, dexmedetomidine; LPS, lipopolysaccharide; ALI, acute lung injury; MPO, myeloperoxidase

Key words: acute lung injury, 3-methyladenine, dexmedetomidine, inflammation, autophagy, TLR4-NF- $\kappa \mathrm{B}$ pathway and albumin in bronchoalveolar fluid and MPO in lung tissue was significantly decreased in the 3-MA and DEX groups compared with the model group $(\mathrm{P}<0.05)$. H\&E staining demonstrated that 3-MA and DEX each reversed the ALI. In addition, 3-MA and DEX reduced the protein expression levels of LC3-I, LC3-II, ATG5, Rab7 and LAMP1. Also, RT-qPCR results revealed that $\mathrm{NF}-\kappa \mathrm{B}$ and TLR4 mRNA expression levels were clearly decreased in the 3-MA and DEX groups compared with the model group. In conclusion, LPS-induced ALI was effectively reversed by treatment with 3-MA and DEX through the reduction of inflammation and autophagy and inhibition of the TLR4-NF- $\mathrm{B}$ pathway.

\section{Introduction}

Acute lung injury (ALI) and acute respiratory distress syndrome (ARDS) are two serious forms of diffuse lung disease, which impose a substantial health burden worldwide (1). They usually occur in association with severe diseases, such as serious infection, burns, trauma and shock, and can be clinically characterized by progressive hypoxemia and respiratory distress, which contributes to alveolar and diffuse pulmonary interstitial edema that is caused by injury to alveolar epithelial cells and pulmonary capillary endothelial cells (2). ALI/ARDS is a major clinical challenge with a high mortality rate of $30-40 \%$ (3). In the past, various interventions and intensive care strategies have been applied to patients with ALI/ARDS. However, only certain supportive treatments utilizing a fluid conservative strategy and lung protective ventilation have been demonstrated to be effective for reducing morbidity and mortality (4). Thus, the development of a novel therapeutic strategy to improve the outcome of ALI/ARDS is required (5).

Despite the intensive research conducted in animals and patients, the etiology and mechanisms of ALI/ARDS have not yet been completely clarified. In previous studies, it has been reported that the systemic inflammatory response caused by multiple pathogenic factors, such as lipopolysaccharide (LPS), plays a vital role $(1,3)$. However, the specific cellular and molecular mechanisms of ALI/ARDS are not completely known (6). Autophagy is a conserved cellular process for the disposal of denatured proteins and damaged organelles through 
a lysosomal degradation pathway that occurs in almost all cells having mitochondria (7). Autophagy executes a homeostatic function in cells when occurring at low basal levels. However, autophagy is rapidly upregulated when intracellular nutrition and/or energy are deficient, such as during starvation, growth factor depletion and in hypoxia (8). It has been indicated that autophagy is associated with a number of pulmonary diseases, including ALI (9). Therefore, the inhibition of autophagy may potentially protect against ALI. 3-methyladenine (3-MA), is a phosphoinositide 3-kinase (PI3K) inhibitor that has been well established as an autophagy inhibitor. Previous studies have indicated that dexmedetomidine (DEX) has protective effects on pulmonary functions in ALI and ventilator-induced lung injury (10).

In the present study, an ALI model was constructed by exposing experimental mice to LPS. The protective effect and underlying therapeutic mechanism of 3-MA and DEX on ALI were subsequently evaluated in this model.

\section{Materials and methods}

Animals and treatments. BALB/c mice $(\mathrm{n}=120 ; 60$ male and 60 female; $20-25 \mathrm{~g}$; 5 weeks) were purchased from the Animal Experimental Center of Southern Medical University (Guangzhou, China). All BALB/c mice were bred in a stainless steel isolation box with free feeding and drinking water. They were kept at a constant temperature $\left(25 \pm 2^{\circ} \mathrm{C}\right)$ and humidity (50-60\%) and exposed to 12-h light/dark cycles. The mice were randomly divided into four groups: Blank group $(\mathrm{n}=30)$, intratracheally injected with $1.00 \mathrm{ml} / \mathrm{kg} 0.9 \%$ saline solution; model group $(\mathrm{n}=30)$, intratracheally injected with 0.2\% LPS (L2630; Sigma-Aldrich; Merck KGaA, Darmstadt, Germany; $3 \mathrm{mg} / \mathrm{kg})$; 3-MA group $(\mathrm{n}=30)$, intraperitoneally injected with $0.2 \%$ LPS ( $3 \mathrm{mg} / \mathrm{kg}$ ), and then intravenously injected with 3-MA (cat no. M9281; Sigma-Aldrich; Merck KGaA) solution (30 mg/kg) $1 \mathrm{~h}$ later; and DEX (cat no. SML0956; Sigma-Aldrich; Merck KGaA) group $(n=30)$, intratracheally injected with $0.2 \%$ LPS solution $(3 \mathrm{mg} / \mathrm{kg})$, and then intravenously injected with DEX solution $(50 \mu \mathrm{g} / \mathrm{kg}) 1 \mathrm{~h}$ later.

The surviving mice in each group were observed at three observation time points: 1,3 and 5 days after injection, and 10 mice from each group were sacrificed under anesthesia at each of these time points. All animal procedures were conducted following the National Institutes of Health guidelines for the care and use of laboratory animals, and the Institutional Animal Care and Use Committee of Zhujiang Hospital approved all the experimental protocols.

Arterial blood gas analysis and lung wet-dry weight ratio $(W / D)$. Carotid arterial blood was immediately collected from the BALB/c mice in each group following sacrifice on days 1, 3 and 5. Moreover, an automated blood gas analyzer (PL1000A; Wincom Co., Ltd., Changsha, China) was used to measure the partial pressure of carbon dioxide $\left(\mathrm{PaCO}_{2}\right)$, partial pressure of oxygen $\left(\mathrm{PaO}_{2}\right)$ and $\mathrm{pH}$ value. In addition, the right upper lung was separated and its wet weight was measured. The right upper lung was then dried in a convection oven (DHG-9030A; Bluepard Instruments Co., Ltd., Shanghai, China) until a constant weight was achieved, and the dry weight was measured. Each example was measured in triplicate. Finally, the W/D was calculated.

Albumin and cytokine content determination in bronchoalveolar lavage fluid $(B A L F)$. On days 1, 3 and 5, sacrificed $\mathrm{BALB} / \mathrm{c}$ mice were intratracheally injected with $0.5 \mathrm{ml} \mathrm{PBS}$ $\left(4^{\circ} \mathrm{C}\right)$ three times. The three BALF samples that were obtained were mixed and then centrifuged at $500 \mathrm{x} \mathrm{g}\left(4^{\circ} \mathrm{C}\right)$ for $10 \mathrm{~min}$. Albumin, tumor necrosis factor (TNF)- $\alpha$ and interleukin (IL)- 6 contents in the supernatant were measured using ELISA kits (ab108792; Abcam, Cambridge, MA, USA; MTA00B and M6000B; R\&D Systems, Inc., Minneapolis, MN, USA), respectively, according to the manufacturer's instructions. Each example was performed in triplicate.

Myeloperoxidase (MPO) assay. MPO content in lung tissue was quantified using a mouse MPO ELISA kit (cat no. ab155458; Abcam). This assay employed a specific antibody against mouse MPO coated on 96-well plates. Crushed lung tissue was centrifuged at $1,000 \mathrm{xg}$ for $10 \mathrm{~min}$ at $4^{\circ} \mathrm{C}$ and the supernatant and standards were added to the wells and MPO in the sample was bound into the wells by the immobilized antibody. After washing, biotinylated anti-mouse antibody was added and the plate was incubated at room temperature for $1 \mathrm{~h}$. The unbound biotinylated antibody was then washed away, and horseradish peroxidase (HRP)-conjugated streptavidin was added to the wells. After washing three times, 3,3',5,5'-tetramethylbenzidine substrate solution was added and color developed in proportion to the content of MPO. The addition of stop solution terminated the color development, and the intensity of the color was measured at $450 \mathrm{~nm}$ using a microplate reader (Biotek Instruments, Inc., Winooski, VT, USA). Each example was performed in triplicate.

Hematoxylin and eosin $(H \& E)$ staining. The lung tissue was fixed in $4 \%$ paraformaldehyde for $10 \mathrm{~min}$ and then cut into $5-\mu \mathrm{m}$ sections. The sections were stained as follows: $70 \%$ ethanol for $10 \mathrm{sec}$, diethyl pyrocarbonate-treated water for $5 \mathrm{sec}$, and then hematoxylin with RNAase inhibitor for $20 \mathrm{sec}, 70 \%$ ethanol for $30 \mathrm{sec}$, eosin $\mathrm{Y}$ in $100 \%$ ethanol for $20 \mathrm{sec}$, followed by dehydration with a series of ethanol for $30 \mathrm{sec}$ each, and finally xylenes for $2 \mathrm{~min}$. The morphometric analysis of alveolar collapse, alveolar hemorrhage, perivascular hemorrhage, vascular congestion, perivascular edema, alveolar edema, alveolar polymorphonuclear leukocytes and macrophages was conducted, as previously described (11). All HE staining experiments were repeated three times.

Western blot analysis. The expression levels of the autophagy-related-proteins microtubule-associated protein 1A/1B-light chain 3 (LC3)-I, LC3-II, autophagy protein 5 (ATG5), Rab7 and lysosome-associated membrane protein 1 (LAMP1) were detected using western blotting. The lung tissue was lysed in radioimmunoprecipitation assay buffer (Beyotime Institute of Biotechnology, Haimen, China) for $2 \mathrm{~h}$ at $4^{\circ} \mathrm{C}$. After centrifugation at $10,000 \mathrm{x} \mathrm{g}$ for $10 \mathrm{~min}$ at room temperature, the protein concentration was determined using a BCA protein assay kit. A total of $80 \mu \mathrm{g}$ per lane of the protein lysates were separated by $12 \%$ gradient sodium dodecyl sulfate-polyacrylamide gel electrophoresis and 
Table I. Primers used in the quantitative polymerase chain reaction.

\begin{tabular}{lll}
\hline Primer & \multicolumn{1}{c}{ Forward (5'-3') } & \multicolumn{1}{c}{ Reverse (5'-3') } \\
\hline NF-kB & CTGAACAAAATGCCCCACGG & TTCCTCCTTTGGGACGATGC \\
TLR4 & AGCCGGAAGGTTATTGTGGT & CAGCAGGGACTTCTCAACCT \\
$18 \mathrm{~S}$ & GAATTCCCAGTAAGTGCGGGTCAT & CGAGGGCCTCACTAAACCATC
\end{tabular}

$\mathrm{NF}-\kappa \mathrm{B}$, nuclear factor- $\kappa \mathrm{B}$; TLR4, Toll-like receptor 4 .

then transferred to PVDF membranes (EMD Millipore, Billerica, MA, USA). The PVDF membranes were blocked with $5 \%(\mathrm{w} / \mathrm{v})$ skimmed milk in TBS with $0.05 \%$ Tween-20 at room temperature for $2 \mathrm{~h}$. After washing three times with TBST, the PVDF membranes were incubated with rabbit polyclonal anti-LC3 (cat no. L8918; Sigma-Aldrich; Merck KGaA; 1:1,000), ATG5 (cat no. ab109490; 1:1,000), Rab7 (cat no. ab50533; 1:2,000) and LAMP1 (cat no., ab25630; 1:10,000; all Abcam) in PBS (0.25\% Triton X and 1\% BSA) at $37^{\circ} \mathrm{C}$ for $2 \mathrm{~h}$. The membranes were then incubated with anti-rabbit or anti-mouse HRP-conjugated secondary antibody (cat no. BA1054; Wuhan Boster Biological Technology, Ltd., Wuhan, China; $1: 5,000)$ for $2 \mathrm{~h}$ at $37^{\circ} \mathrm{C}$. The control GAPDH (Abcam; cat no. ab181602; 1:10,000) levels were used for the normalization. Visualization with ECL detection reagents (Pierce; Thermo Fisher Scientific, Inc.). The protein bands were scanned with a ChemiDoc image analysis system (Bio-Rad Laboratories, Inc., Hercules, CA, USA) and quantified with Image $\mathrm{J} 2 \mathrm{x}$ software (National Institutes of Health, Bethesda, MD, USA). All western blot experiments were repeated three times.

Reverse transcription-quantitative polymerase chain reaction $(R T-q P C R)$. Total RNA was extracted from lung tissue using an RNA Extraction kit (Invitrogen; Thermo Fisher Scientific, Inc., Waltham, MA, USA). The concentration of total RNA was determined by measuring the absorbance at $260 \mathrm{~nm}$. The total RNA $(0.5 \mu \mathrm{g})$ was employed for cDNA synthesis using a cDNA Synthesis kit (cat no. 6210A; Takara, Biotechnology Co., Ltd., Dalian, China) according to the manufacturer's protocols and subsequently the cDNA was diluted using nuclease-free water to a concentration of $10 \mathrm{ng} / \mu \mathrm{l}$. The primers used for PCR are shown in Table I. PCR was accomplished by a hotstart SYBR-green-based method (VeriQuest SYBR-Green qPCR Master Mix, Invitrogen; Thermo Fisher Scientific, Inc.). Gene fold-changes were determined using the $\Delta \Delta \mathrm{Cq}$ method (12) and utilizing $18 \mathrm{~S}$ rRNA for normalization. DNA was amplified at $94^{\circ} \mathrm{C}$ for $3 \mathrm{~min}$, followed by 35 cycles of $94^{\circ} \mathrm{C}$ for $15 \mathrm{sec}$ and at $60^{\circ} \mathrm{C}$ for $15 \mathrm{sec}$. All RT-qPCR experiments were performed in triplicate and repeated twice.

Statistical analysis. Data are presented as the mean \pm standard error of the mean and were analyzed using SPSS 13.0 statistical software (SPSS Inc., Chicago, IL, USA). Data from multiple groups were analyzed using analysis of variance with repeated measures. The post-hoc test of least significant difference was used where equal variances were assumed and Dunnett's T3 test was used when equal variances were not assumed. A value of $\mathrm{P}<0.05$ was considered to indicate a statistically significant difference.

\section{Results}

Arterial blood gas analysis and lung W/D. The results of arterial blood gas analysis, $\mathrm{pH}$ analysis and W/D calculations are presented in Table II. In the model group, W/D and $\mathrm{PaCO}_{2}$ were elevated and $\mathrm{PaO}_{2}$ was reduced compared with those in the blank group (both $\mathrm{P}<0.05$ ). These results implied that the ALI model was successfully established. At each time point, $\mathrm{PaCO}_{2}$ and W/D in the 3-MA and DEX groups were lower compared with those in the model group (both $\mathrm{P}<0.05$ ), and the $\mathrm{PaO}_{2}$ values in the 3-MA and DEX groups were higher compared with those in the model group $(\mathrm{P}<0.05)$. No significant difference was identified in $\mathrm{pH}$ value among the four groups (all $\mathrm{P}>0.05$ ).

Albumin, cytokine and MPO contents. The ELISA results for albumin and cytokines (TNF- $\alpha$ and IL-6) in BALF and MPO in lung tissue are shown in Table III. The levels of albumin, TNF- $\alpha$ and IL- 6 in the BALF were significantly increased in the model group compared with the blank group $(\mathrm{P}<0.05)$. Furthermore, the levels of TNF- $\alpha$, IL-6, MPO and albumin were significantly decreased in the BALF in the 3-MA or DEX groups when compared with the model group $(\mathrm{P}<0.05)$.

$H \& E$ staining. H\&E staining images for samples from day 1 are displayed in Fig. 1. In the blank group, H\&E staining revealed thin alveolar walls and clear alveolar structures. Moreover, no hyperemia or widening was observed in the alveolar septum and no symptoms of bleeding and inflammatory cell infiltration were detected (Fig. 1A). In the model group, pulmonary interstitial and alveolar edema progressed rapidly, and alveolitis was clearly observed. Diffuse pulmonary hemorrhage, vascular endothelial cell injury, the formation of hyaline membranes and alveolar collapse occurred, and a heavy infiltration of inflammatory cells was visible in the alveolar space, accompanied by slight hemorrhage and edema (Fig. 1B). In the 3-MA and DEX groups, pulmonary lesions were comparable. It was observed macroscopically that the lung was slightly enlarged and the bleeding points and ecchymosis were visible in sections of the lung. The surface of the lung tissues was uneven locally, with a scattering of small white nodules. However, observation of the images in Fig. 1C and D indicates that the protective effect of 3-MA was particularly evident. The $\mathrm{H} \& \mathrm{E}$ staining results for samples taken on days 3 and 5 were 
Table II. Comparison of $\mathrm{PaO}_{2}, \mathrm{PaCO}_{2}$, $\mathrm{pH}$ value and W/D among the groups on days 1,3 and 5 following the intratracheal injection of lipopolysaccharide.

\begin{tabular}{lcccccc}
\hline Group & Day & $\mathrm{n}$ & $\mathrm{PaO}_{2}(\mathrm{mmHg})$ & $\mathrm{PaCO}_{2}(\mathrm{mmHg})$ & $\mathrm{pH}$ value \\
\hline Blank group & 1 & 10 & $115.34 \pm 2.35$ & $33.25 \pm 1.20$ & $7.38 \pm 0.06$ & $5.74 \pm 0.29$ \\
& 3 & 10 & $116.04 \pm 1.86$ & $34.21 \pm 1.25$ & $7.35 \pm 0.05$ & $5.76 \pm 0.31$ \\
Model group & 5 & 10 & $114.95 \pm 2.31$ & $33.86 \pm 1.37$ & $7.34 \pm 0.07$ & $5.77 \pm 0.25$ \\
& 1 & 10 & $82.50 \pm 1.67^{\mathrm{a}}$ & $50.35 \pm 1.85^{\mathrm{a}}$ & $7.28 \pm 0.05^{\mathrm{a}}$ & $7.68 \pm 0.56^{\mathrm{a}}$ \\
& 3 & 10 & $85.38 \pm 2.58^{\mathrm{a}}$ & $51.34 \pm 1.36^{\mathrm{a}}$ & $7.22 \pm 0.06^{\mathrm{a}}$ & $7.88 \pm 0.65^{\mathrm{a}}$ \\
3-MA group & 5 & 10 & $88.85 \pm 3.12^{\mathrm{a}}$ & $49.37 \pm 2.01^{\mathrm{a}}$ & $7.30 \pm 0.07^{\mathrm{a}}$ & $7.84 \pm 0.63^{\mathrm{a}}$ \\
& 1 & 10 & $109.75 \pm 1.65^{\mathrm{b}}$ & $38.56 \pm 1.76^{\mathrm{b}}$ & $7.35 \pm 0.05^{\mathrm{b}}$ & $6.35 \pm 0.27^{\mathrm{b}}$ \\
DEX group & 3 & 10 & $110.68 \pm 2.30^{\mathrm{b}}$ & $39.86 \pm 1.48^{\mathrm{b}}$ & $7.36 \pm 0.07^{\mathrm{b}}$ & $6.32 \pm 0.28^{\mathrm{b}}$ \\
& 5 & 10 & $112.45 \pm 1.60^{\mathrm{b}}$ & $40.25 \pm 2.34^{\mathrm{b}}$ & $7.37 \pm 0.04^{\mathrm{b}}$ & $6.28 \pm 0.31^{\mathrm{b}}$ \\
& 1 & 10 & $98.55 \pm 1.86^{\mathrm{b}}$ & $42.35 \pm 1.86^{\mathrm{b}}$ & $7.36 \pm 0.06^{\mathrm{b}}$ & $6.64 \pm 0.35^{\mathrm{b}}$ \\
& 3 & 10 & $99.35 \pm 2.75^{\mathrm{b}}$ & $41.35 \pm 2.05^{\mathrm{b}}$ & $7.37 \pm 0.05^{\mathrm{b}}$ & $6.62 \pm 0.44^{\mathrm{b}}$ \\
\hline
\end{tabular}

Data are presented as the mean $\pm \mathrm{SEM}$. Each result represents the mean of three independent experiments carried out in triplicate. $\mathrm{PaO}_{2}$, partial pressure of oxygen; $\mathrm{PaCO}_{2}$, partial pressure of carbon dioxide; W/D, lung wet-dry weight ratio; 3-MA, 3-methyladenine; DEX, dexmedetomidine. ${ }^{\mathrm{a}} \mathrm{P}<0.05$ vs. the model group. ${ }^{\mathrm{b}} \mathrm{P}<0.05$ vs. the model group.

Table III. Comparison of TNF- $\alpha$, IL-6 and albumin content in BALF and MPO content in lung tissue among the groups on day 1, 3 and 5 following the intratracheal injection of lipopolysaccharide.

\begin{tabular}{lcccccc}
\hline Group & Day & $\mathrm{n}$ & TNF- $\alpha(\mathrm{pg} / \mathrm{ml})$ & IL-6 $(\mathrm{pg} / \mathrm{ml})$ & MPO (ng/ml) & Albumin $(\mathrm{ng} / \mathrm{ml})$ \\
\hline Blank group & 1 & 10 & $101.06 \pm 4.32$ & $90.25 \pm 4.65$ & $20.34 \pm 1.35$ & $48.67 \pm 3.35$ \\
& 3 & 10 & $102.34 \pm 3.86$ & $91.34 \pm 4.85$ & $21.38 \pm 1.42$ & $49.35 \pm 5.26$ \\
Model group & 5 & 10 & $103.34 \pm 2.65$ & $92.37 \pm 3.65$ & $20.24 \pm 1.37$ & $50.31 \pm 4.96$ \\
& 1 & 10 & $612.35 \pm 5.63^{\mathrm{a}}$ & $402.36 \pm 5.67^{\mathrm{a}}$ & $80.34 \pm 1.65^{\mathrm{a}}$ & $183.24 \pm 6.68^{\mathrm{a}}$ \\
& 3 & 10 & $604.35 \pm 5.84^{\mathrm{a}}$ & $398.36 \pm 5.34^{\mathrm{a}}$ & $82.35 \pm 2.47^{\mathrm{a}}$ & $180.27 \pm 5.48^{\mathrm{a}}$ \\
3-MA group & 5 & 10 & $593.68 \pm 4.67^{\mathrm{a}}$ & $390.25 \pm 6.31^{\mathrm{a}}$ & $81.35 \pm 2.36^{\mathrm{a}}$ & $173.26 \pm 6.04^{\mathrm{a}}$ \\
& 1 & 10 & $204.63 \pm 3.64^{\mathrm{b}}$ & $200.45 \pm 5.28^{\mathrm{b}}$ & $41.25 \pm 2.32^{\mathrm{b}}$ & $98.34 \pm 5.55^{\mathrm{b}}$ \\
DEX group & 3 & 10 & $201.32 \pm 2.86^{\mathrm{b}}$ & $192.24 \pm 4.67^{\mathrm{b}}$ & $42.15 \pm 2.41^{\mathrm{b}}$ & $94.31 \pm 5.22^{\mathrm{b}}$ \\
& 5 & 10 & $195.75 \pm 3.68^{\mathrm{b}}$ & $188.57 \pm 4.35^{\mathrm{b}}$ & $40.85 \pm 1.33^{\mathrm{b}}$ & $90.38 \pm 6.33^{\mathrm{b}}$ \\
& 1 & 10 & $285.64 \pm 4.56^{\mathrm{b}}$ & $300.35 \pm 5.86^{\mathrm{b}}$ & $51.58 \pm 2.46^{\mathrm{b}}$ & $152.39 \pm 5.28^{\mathrm{b}}$ \\
& 3 & 10 & $279.49 \pm 5.36^{\mathrm{b}}$ & $286.34 \pm 5.26^{\mathrm{b}}$ & $50.22 \pm 1.41^{\mathrm{b}}$ & $143.37 \pm 6.24^{\mathrm{b}}$ \\
\hline
\end{tabular}

Data are presented as the mean \pm SEM. Each result represents the mean of three independent experiments carried out in triplicate. TNF, tumor necrosis factor; IL, interleukin; MPO, myeloperoxidase; 3-MA, 3-methyladenine; DEX, dexmedetomidine. ${ }^{\text {a }}<0.05$ vs. the model group. ${ }^{\mathrm{b}} \mathrm{P}<0.05$ vs. the model group.

similar to those on day 1 . The H\&E staining demonstrated that 3-MA and DEX are able to alleviate the pathological changes of acute alveolitis in mice.

Western blot analysis. Western blotting was used to detect changes in the LC3-II/I ratio in order to evaluate the occurrence of autophagy. A higher LC3-II/I ratio is indicative of a higher level of autophagy (13). The LC3-II/I ratio was higher in the model group compared with the blank group. In addition, compared with the blank group, the expression levels of ATG5, Rab7 and LAMP1 were upregulated in the model group $(\mathrm{P}<0.05)$. This indicates that LPS increased the level of autophagy in mice. However, when the ALI model mice were treated with 3-MA or DEX, the LC3-II/I ratio, and ATG5, Rab7 and LAMP1 expression levels were downregulated $(\mathrm{P}<0.05)$. These results indicate that 3-MA and DEX are able to reduce autophagy (Fig. 2). The results shown in Fig. 2 are those for samples taken on day 1; the results for samples taken on days 3 and 5 (data not shown) were similar to those on day 1 .

RT-qPCR analysis. In order to detect the effect of 3-MA and DEX on the autophagy-related signaling pathway, this experiment evaluated the expression levels of nuclear factor- $\kappa \mathrm{B}(\mathrm{NF}-\kappa \mathrm{B})$ and Toll-like receptor 4 (TLR4) using 

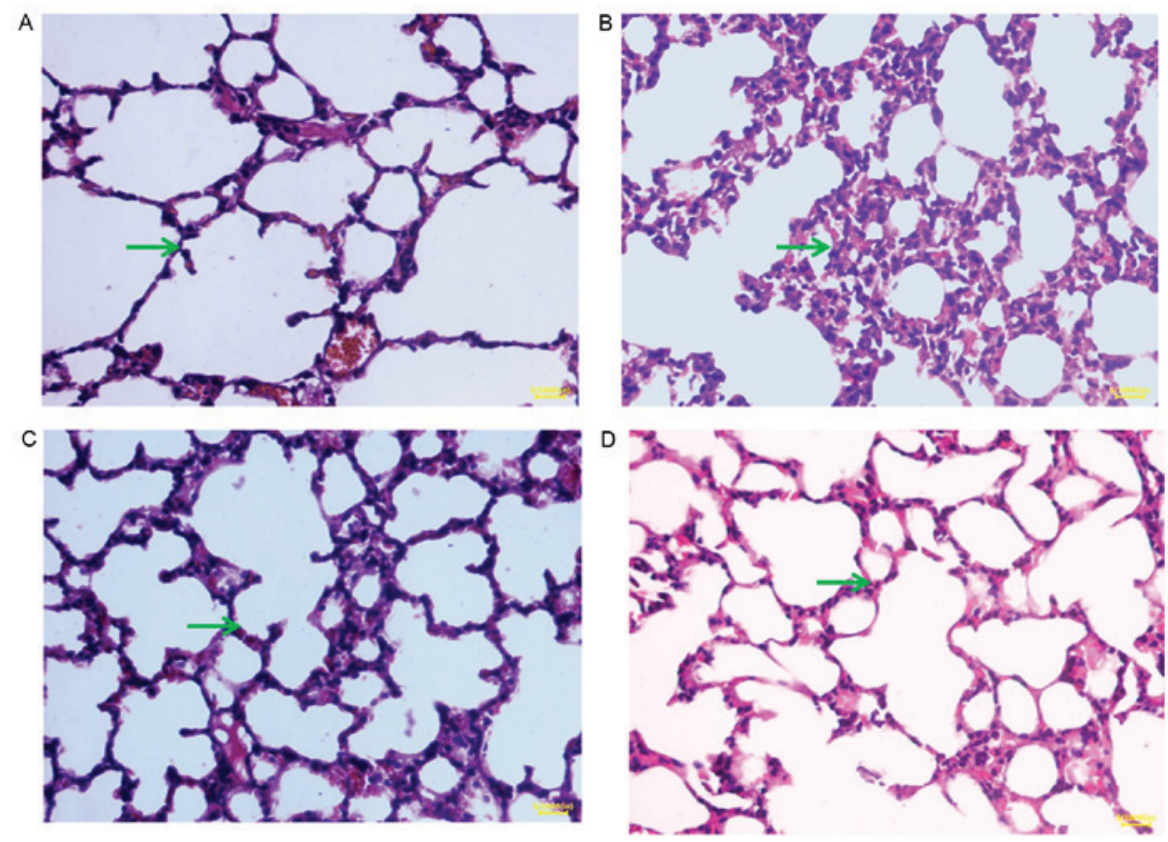

Figure 1. Pathological changes in mouse lung tissues observed by hematoxylin and eosin staining (magnification, x400; scale bar, $200 \mu \mathrm{m}$ ). (A) Blank group, (B) model group, (C) 3-methyladenine group and (D) dexmedetomidine group. The green arrow indicates the symptoms of bleeding and inflammatory cell infiltration.
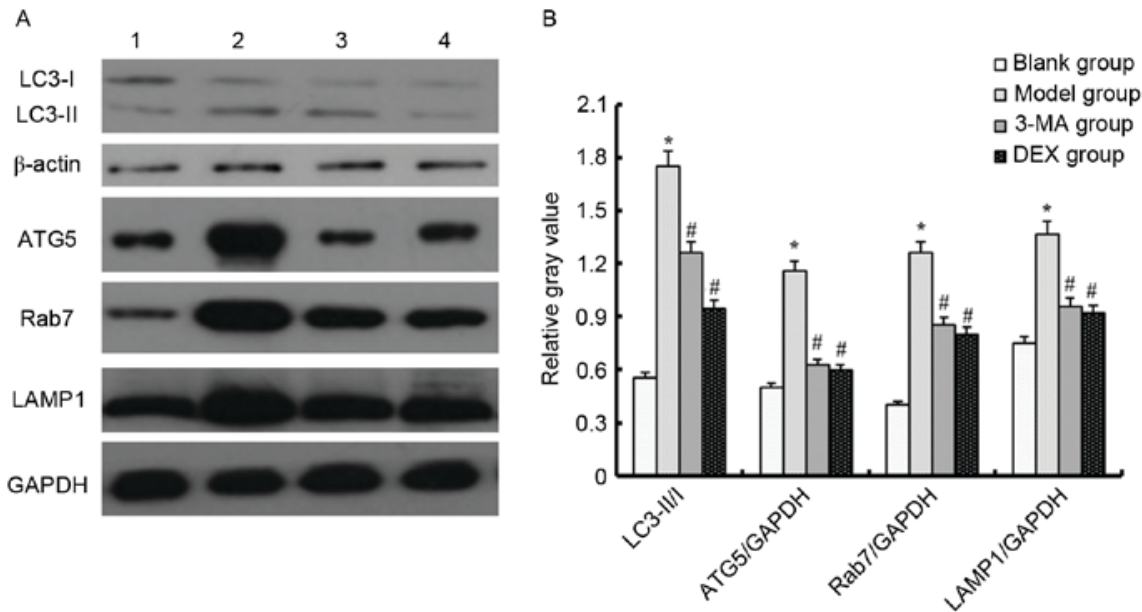

Figure 2. Autophagy related-protein expression level in each group as determined by western blotting. (A) Representative western blots are shown. Lane 1, blank group; lane 2, model group; lane 3, 3-MA group; lane 4, DEX group. (B) Relative gray values for LC3-II/I, ATG5/GAPDH, Rab7/GAPDH and LAMP1/GAPDH. ${ }^{*} \mathrm{P}<0.05$ vs. the blank group; ${ }^{*} \mathrm{P}<0.05$ vs. the model group. LC3, microtubule-associated protein $1 \mathrm{~A} / 1 \mathrm{~B}$-light chain 3; ATG5, autophagy protein 5; LAMP1, lysosome-associated membrane protein 1; 3-MA, 3-methyladenine; DEX, dexmedetomidine.

RT-qPCR (Fig. 3). In the LPS-induced ALI model mice, the mRNA expression levels of NF- $\kappa$ B and TLR4 were upregulated compared with those in the blank group $(\mathrm{P}<0.05)$. Following treatment of the mice with 3-MA, the mRNA expression levels of NF- $\mathrm{KB}$ and TLR4 were downregulated $(\mathrm{P}<0.05)$. The mice in the DEX group exhibited similar downregulation of these mRNAs $(\mathrm{P}<0.05)$. The results shown in Fig. 3 are those for samples taken on day 1 ; the results for samples taken on days 3 and 5 (data not shown) were similar to those on day 1.

\section{Discussion}

The pathogenesis of ALI is considered to involve injury of the alveolar epithelium and vascular endothelium. Neutrophils

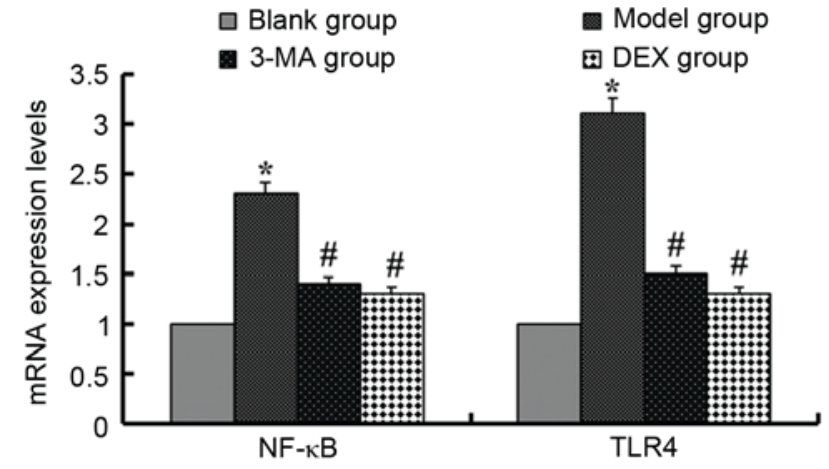

Figure 3. mRNA expression levels of NF- $\kappa \mathrm{B}$ and TLR4 in each group. ${ }^{*} \mathrm{P}<0.05$ vs. the blank group, ${ }^{\#} \mathrm{P}<0.05$ vs. the model group. $\mathrm{NF}-\kappa \mathrm{B}$, nuclear factor- $\kappa \mathrm{B}$; TLR4, Toll-like receptor 4; 3-MA, 3-methyladenine; DEX, dexmedetomidine. 
and leukocytes serve a vital role in the pathogenesis of ALI/ARDS (2). The high expression of pro-inflammatory mediators (for example, TNF, IL-1, IL-8 and IL-6) is considered a direct manifestation of cellular injury (14). Furthermore, numerous studies have indicated that $\mathrm{NF}-\kappa \mathrm{B}$ is activated following the exposure of an animal or human body to LPS and activated NF- $\mathrm{B}$ is important in the regulation of inflammatory mediator transcription $(15,16)$. Under the stimulation of LPS or TNF- $\alpha$, neutrophils exhibit activation of $\mathrm{NF}-\kappa \mathrm{B}, \mathrm{Akt}$ and $\mathrm{p} 38$, and this early activation of neutrophils has been shown to be associated with ventilator time and treatment modality in patients with ALI (17). MPO is characteristic of neutrophils; the content of MPO reflects the antioxidant ability of neutrophils (18). Alveolar macrophages are also very important in the inflammatory response that leads to cell damage in ALI; a variety of cytokines are produced by macrophages that contribute to the initiation of ALI, including TNF- $\alpha$, IL- 6 , IL-1 $\beta$, IL-8 and interferon- $\gamma$ (14). In a previous study of ALI, 3-MA reduced the lung weight coefficient and content of TNF- $\alpha$ in the BALF, and increased $\mathrm{PaO}_{2}$ (9). The anti-inflammatory effect of DEX has been demonstrated in previous experimental animal models $(19,20)$. The present study confirmed the anti-inflammatory effects of 3-MA and DEX.

3-MA, as a PI3K inhibitor, Liu et al (9) found that 3-MA partly ameliorated seawater-induced ALI through the inhibition of autophagy. DEX is a selective $\alpha 2$-adrenergic agonist used for analgesia and sedation in critically ill patients (21). The mechanism of the protective effect of DEX on ALI is not clear; however, Xie et al (22) demonstrated that DEX ameliorated intestinal I/R-induced lung injury via the reduction of autophagy and apoptosis. Furthermore, Zhang et al (23) revealed that DEX inhibited neuronal autophagy mediated by activation of the PI3K/Akt/mechanistic target of rapamycin (mTOR) pathway in the hippocampus. In the present study, 3-MA and DEX treatment decreased the expression of autophagy-related proteins and inhibited autophagy.

TLR4 activity participates in cytoplasmic sequestration and subsequent recycling or degradation by connecting autophagy to phagocytosis so that autophagy acts as an effector of TLR4 signaling to eliminate invasive pathogens, apoptotic/dead cells and debris (24). In a previous study, TLR4 was demonstrated to act as a negative regulator of noninfectious lung inflammation induced by low-molecular-weight hyaluronic acid (25). Furthermore, Doi et al (26) established an ALI model using TLR4-mutant $(\mathrm{C} 3 \mathrm{H} / \mathrm{HeJ})$ mice and TLR4-wild-type $(\mathrm{C} 3 \mathrm{H} / \mathrm{HeN})$ mice, and the results indicated that $\mathrm{C} 3 \mathrm{H} / \mathrm{HeJ}$ mice had significantly decreased expression levels of inflammatory cytokines and were protected against ALI. It has been reported that TLR4 deficiency not only inhibits the formation of autophagosomes, but also results in decreased numbers of autophagosomes in lung tissue (24). On the basis of the present study and other observations (27), it appears that activation of TLR4 induces autophagy by inhibiting the PI3K-Akt-mTOR pathway. Thus, the present study supports the notion that basal TLR4 activity, particularly TLR4-induced autophagy, is required for the early and effective clearance of injured or dead cells, unfolded/misfolded proteins, or debris in injured lung tissue and for the resolution of chronic inflammation and fibrosis following tissue injury (24). In the present study,
3-MA and DEX decreased TLR4 expression, and resulted in a reduction in autophagosomes, as indicated by the decreased expression of autophagy-related proteins.

In summary, the present study confirmed that 3-MA and DEX have comparable effects on ALI; both of them protect against ALI through reducing the inflammatory response and inhibiting autophagy-related proteins and the autophagy-related signaling pathway. The efficacy of 3-MA and DEX in attenuating the LPS-induced ALI was similar. The results indicate that LPS-induced ALI was effectively reversed with 3-MA or DEX through the reduction of inflammation and autophagy, and inhibition of the TLR 4-NF- $\kappa$ B pathway.

\section{Acknowledgements}

The present study was funded by the National Natural Science Foundation of China (grant no. 81271390) and the Science and Technology Project of Shenzhen (grant no. JCYJ20140416122812032).

\section{Competing interests}

The authors declare that they have no competing interests.

\section{References}

1. Wang L, Chen JM, Wang B, Wu DQ, Li H, Lu H, Wu H and Chai Y: Protective effect of quercetin on lipopolysaccharide-induced acute lung injury in mice by inhibiting inflammatory cell influx. Exp Biol Med (Maywood) 239: 1653-1662, 2014.

2. Herold S, Gabrielli NM and Vadász I: Novel concepts of acute lung injury and alveolar-capillary barrier dysfunction. Am J Physiol Lung Cell Mol Physiol 305: L665-L681, 2013.

3. Matthay MA and Howard JP: Progress in modelling acute lung injury in a pre-clinical mouse model. Eur Respir J 39: 1062-1063, 2012.

4. de Haro C, Martin-Loeches I, Torrents E and Artigas A: Acute respiratory distress syndrome: Prevention and early recognition. Ann Intensive Care 3: 11, 2013.

5. Griet M,Zelaya H, Mateos MV, Salva S, Juarez GE, de Valdez GF, Villena J, Salvador GA and Rodriguez AV: Soluble factors from Lactobacillus reuteri CRL1098 have anti-Inflammatory effects in acute lung injury induced by lipopolysaccharide in mice. PLoS One 9: e110027, 2014.

6. Zhao LL, Hu GC, Zhu SS, Li JF and Liu GJ: Propofol pretreatment attenuates lipopolysaccharide-induced acute lung injury in rats by activating the phosphoinositide-3-kinase/Akt pathway. Braz J Med Biol Res 47: 1062-1067, 2014

7. Ryter SW, Nakahira K, Haspel JA and Choi AM: Autophagy in pulmonary diseases. Annu Rev Physiol 74: 377-401, 2012.

8. Levine B and Kroemer G: Autophagy in the pathogenesis of disease. Cell 132: 27-42, 2008.

9. Liu QP, Zhou DX, Lin P, Gao XL, Pan L and Jin FG: Participation of autophagy in acute lung injury induced by seawater. Exp Lung Res 39: 441-452, 2013.

10. Sen V, Güzel A, Şen HS, Ece A, Uluca U, Söker S, Doğan E, Kaplan İ and Deveci E: Preventive effects of dexmedetomidine on the liver in a rat model of acid-induced acute lung injury. Biomed Res Int 2014: 621827, 2014.

11. Wu Q, Li R, Soromou L, Chen N, Yuan X, Sun G, Li B and Feng H: p-Synephrine suppresses lipopolysaccharide-induced acute lung injury by inhibition of the NF-kB signaling pathway. Inflamm Res 63: 429-439, 2014.

12. Livak KJ and Schmittgen TD: Analysis of relative gene expression data using real-time quantitative PCR and the 2(-Delta Delta C(T)) method. Methods 25: 402-408, 2001.

13. Karim M, Kanazawa T, Daigaku Y, Fujimura S, Miotto G and Kadowaki M: Cytosolic LC3 ratio as a sensitive index of macroautophagy in isolated rat hepatocytes and H4-II-E cells. Autophagy 3: 553-560, 2007. 
14. Yang KY, Arcaroli JJ and Abraham E: Early alterations in neutrophil activation are associated with outcome in acute lung injury. Am J Respir Crit Care Med 167: 1567-1574, 2003.

15. Minhajuddin M, Fazal F, Bijli KM, Amin MR and Rahman A: Inhibition of mammalian target of rapamycin potentiates thrombin-induced intercellular adhesion molecule-1 expression by accelerating and stabilizing NF-kappa B activation in endothelial cells. J Immunol 174: 5823-5829, 2005.

16. Wang S, Li Y, Fan J, Wang Z, Zeng X, Sun Y, Song P and Ju D: The role of autophagy in the neurotoxicity of cationic PAMAM dendrimers. Biomaterials 35: 7588-7597, 2014.

17. Hu Y, Liu J, Wu YF, Lou J, Mao YY, Shen HH and Chen ZH: mTOR and autophagy in regulation of acute lung injury: A review and perspective. Microbes Infect 16: 727-734, 2014.

18. Xiao H, Heering P, Hu P, Liu Z, Zhao M, Aratani Y, Maeda N, Falk RJ and Jennette JC: Antineutrophil cytoplasmic autoantibodies specific for myeloperoxidase cause glomerulonephritis and vasculitis in mice. J Clin Invest 110: 955-963, 2002

19. Yang CL, Tsai PS and Huang CJ: Effects of dexmedetomidine on regulating pulmonary inflammation in a rat model of ventilator-induced lung injury. Acta Anaesthesiol Taiwan 46: 151-159, 2008.

20. Can M, Gul S, Bektas S, Hanci V and Acikgoz S: Effects of dexmedetomidine or methylprednisolone on inflammatory responses in spinal cord injury. Acta Anaesthesiol Scand 53: 1068-1072, 2009.

21. Gertler R, Brown C, Mitchell DH and Silvius EN: Dexmedetomidine: A novel sedative-analgesic agent. Proc (Bayl Univ Med Cent) 14: 13-21, 2001.
22. Xie C, Li Y, Liang J, Xiao J, Zhao Z and Li T: The effect of dexmedetomidine on autophagy and apoptosis in intestinal ischemia reperfusion-induced lung injury. Zhonghua Jie $\mathrm{He} \mathrm{He}$ Hu Xi Za Zhi 38: 761-764, 2015 (In Chinese).

23. Zhang MH, Zhou XM, Gao JL, Wang KJ and Cui JZ: PI3K/Akt/mTOR pathway participates in neuroprotection by dexmedetomidine inhibits neuronic autophagy following traumatic brain injury in rats. Int J Res Med Sci 2: 1569-1575, 2014.

24. Yang HZ, Wang JP, Mi S, Liu HZ, Cui B, Yan HM, Yan J, Li Z, Liu H, Hua F, et al: TLR4 activity is required in the resolution of pulmonary inflammation and fibrosis after acute and chronic lung injury. Am J Pathol 180: 275-292, 2012.

25. Zhao H, Leu SW, Shi L, Dedaj R, Zhao G, Garg HG, Shen L, Lien E, Fitzgerald KA, Shiedlin A, et al: TLR4 is a negative regulator in noninfectious lung inflammation. J Immunol 184: 5308-5314, 2010.

26. Doi K, Ishizu T, Tsukamoto-Sumida M, Hiruma $T$, Yamashita T, Ogasawara E, Hamasaki Y, Yahagi N, Nangaku $\mathrm{M}$ and Noiri E: The high-mobility group protein B1-Toll-like receptor 4 pathway contributes to the acute lung injury induced by bilateral nephrectomy. Kidney Int 86: 316-326, 2014.

27. Yen YT, Yang HR, Lo HC, Hsieh YC, Tsai SC, Hong CW and Hsieh $\mathrm{CH}$ : Enhancing autophagy with activated protein $\mathrm{C}$ and rapamycin protects against sepsis-induced acute lung injury. Surgery 153: 689-698, 2013. 